\section{Thermoviscous bulk-fill composite}

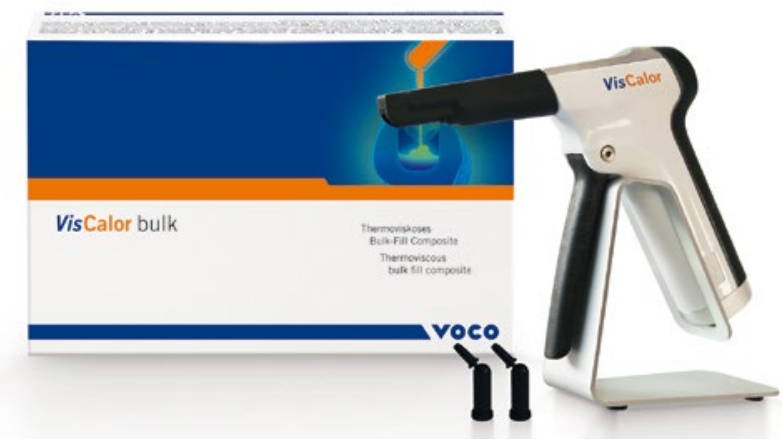

VisCalor bulk is the world's first restorative material with 'thermoviscous technology', which has been specially developed for warming up. The extraoral warming means that the composite can initially be placed in the cavity in flowable form, but then changes its consistency within a few seconds to become sculptable.

VisCalor bulk is warmed to approx. $68^{\circ} \mathrm{C}$ before it can be applied. It is also a $4 \mathrm{~mm}$ bulk material and does not need to be applied in layers. VisCalor bulk is available in four shades (A1, A2, A3, universal) and covers the entire indication range for classes I, II and V restorations.

The VisCalor Dispenser is the perfect device to use in combination with VisCalor bulk. This material is the world's first nanohybrid composite specially developed for heating up. The increase in temperature gives the material a lower viscosity, allowing it to flow optimally on margins and undercut regions. This also prevents air bubbles and minimises the risk of marginal gaps. The VisCalor Dispenser has two heating programmes: one for VisCalor bulk and one for all other VOCO composites.

www.voco.dental,info@voco.com

\section{The CAD/CAM block that can stand the pressure}

Strong, flexible and aesthetic - these are the key attributes that restorative clinicians require in a dental CAD/CAM block, for milling long-lasting, beautiful restorations.

Thank goodness then for CERASMART270, GC UK's forceabsorbing hybrid ceramic dental CAD/CAM block.

The secret of its success is the Full Coverage Silane Coating (FSC) technology. This advanced nanofiller technology gives the blocks a high filler rate, providing high flexural strength and resistance to fracture, as well as improved flexibility to absorb shock.

These attributes make CERASMSART270 ideal for use in all areas of the mouth, particularly those which take the full force of masticatory pressure, which gives it an added indication for bruxist patients. This is further helped by the ultra-fine fillers which are coated with silane and so cause very low wear on the opposing dentition.

The silane coating also furnishes CERASMART270 with a long-lasting gloss which contributes to the material's durable gloss finish, smooth feel and excellent aesthetics. The blocks come in a variety of warm colours with natural fluorescence and opalescence and it is the only hybrid ceramic dental CAD/CAM milling block that can be either sandblasted or pre-treated with hydrofluoric acid.

CERASMART270 can be milled quickly and precisely with superb marginal adaptation, and its high radiopacity makes follow-ups straightforward. Strong, flexible, aesthetic, easy to use and long-lasting - CERASMART270 is the dental CAD/CAM block which can truly stand the pressure.

To find out more contact GC UK Ltd on 01908 218999, email info.uk@gc.dental or visitwww.gceurope.com.

\title{
Thumb sucking prevention glove earns accreditation
}

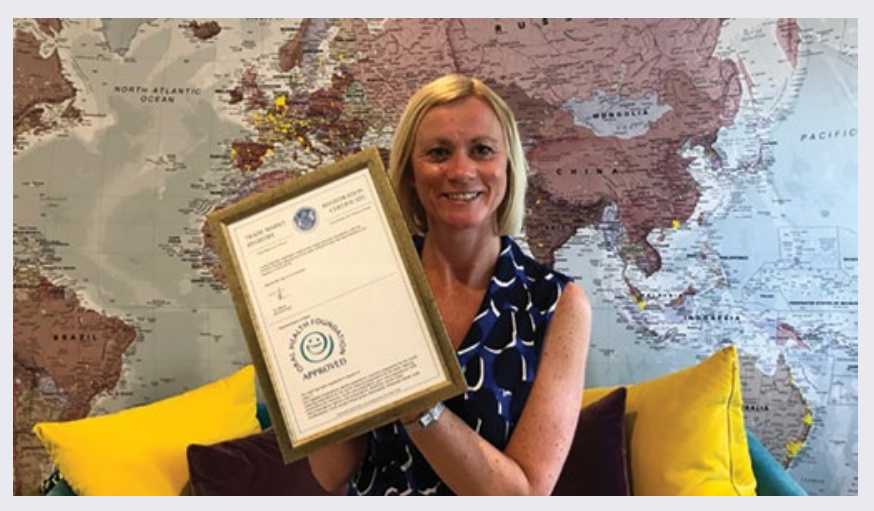

Thumb sucking prevention tool Thumbsie has received Product Accreditation from the Oral Health Foundation.

Thumbsie works alongside dentists to help to stop children thumb sucking which can create dental problems such as overbite, misaligned teeth and even a malformed palate, which can lead to painful and prolonged dental treatment.

Experts at the Oral Health Foundation said that Thumbsie had included substantial anecdotal statements from the public verifying how this product had helped 'break the habit' of thumb/finger sucking in children.

Thumbsie was created in 2013 when Jo Bates (pictured) couldn't find an effective solution for her own daughter's thumb sucking problems. She made a fabric thumb guard which stopped her daughter sucking within five weeks. Seeing a gap in the market she launched her business and has been helping other families who are struggling with thumb and finger sucking ever since.

The Thumbsie is all the more relevant during the current COVID-19 pandemic as thumb sucking could help a virus get into the moist parts of the face (eyes, mouth, nose). A Thumbsie can make giving up faster and easy, reducing the chances of infection.

The Thumbsie thumb guard is available in over 40 child friendly fabric patterns to choose from which means that there will be something that everyone can enjoy wearing, whether it is unicorns or trucks.

The glove is secured around the wrist using Velcro. The glove comes in five different sizes; it has a simple measuring guide, which helps the guard to fit well on either hand. The product covers the thumb or finger and acts as a constant reminder when a child puts their thumb in their mouth.

To find out more about Thumbsie visit www.thumbsie.co.uk. 